\title{
Cervical tarlov cyst mimicking spinal hydatid disease: case report
}

\section{Abstract}

Background: Perineurial (Tarlov) cysts are usually incidental findings during magnetic resonance imaging of the lumbosacral spine. The Cervical localisation have been reported to be a rare occurance. We are reporting a case where a high cervical perineural cyst was masquerading as a spinal hydatid disease.

Case presentation:We report a case of symptomatic cervical Tarlov cyst in a 9 years old girl operated on twice for pulmonary and hepatic hydatid cyst. Spinal magnetic resonance imaging (MRI) showed an extradural intraspinal lesion with fluid-equivalent signal extending from $\mathrm{C} 5$ to $\mathrm{T} 2$. Based on the history, the diagnosis of spinal hydatid disease was suggested. Surgical excision of the cyst resulted in significant improvement in patient symptoms, and histological examination revealed the diagnosis of a Tarlov cyst.

Conclusion: Cervical perineural (Tarlov) cyst can be symptomatic by causing nerve root compression and can be mistaken as a spinal hydatid disease on imaging. Surgical treatment can be curative.
Volume 9 Issue 6 - 2019

\section{Marouane Hammoud, Fayçal Lakhdar, Mohammed Benzagmout, Khalid Chakour , Mohammed El Faiz Chaoui \\ Department of Neurosurgery, Hassan II University Hospital of Fez, Morocco}

Correspondence: Marouane Hammoud, Medicine doctor, Department of Neurosurgery, Hassan II University Hospital of Fez, Morocco, University Sidi Mohammed Ben Abdellah, Fez, Morocco, Tel 002/266/49/896,

Email marouane.hammou@gmail.com

Received: October 21, 2019 | Published: November 26, 2019

Keywords: Tarlov cyst, hydatid cyst, diagnosis, management MRI, cervical spine.

Abreviations: TC, tarlov cyst; CSF, cerebrospinal fluid; MRI, magnetic resonance imaging

\section{Introduction}

Tarlov cyst (TC) is defined as a cystic dilatation between the perineurium and endoneurium of spinal nerve roots, located at level of the spinal ganglion and filled with cerebrospinal fluid (CSF) but without communication with the perineurial subarachnoid space. ${ }^{1}$ It is most often found in the sacral spine with a prevalence of $4.6 \%$ in the general population with about $13 \%$ of those being symptomatic. ${ }^{1,2}$ The Cervical localisation have been reported to be a rare occurance, ${ }^{3}$ to our knowledge there are only five published cases of symptomatic cervical Tarlov cyst. ${ }^{4}$ Here in a case of symptomatic cervical TC that was masquerading as a spinal hydatid disease.

\section{Case presentation}

A 9-year-old girl, with medical history of surgery for pulmonary and hepatic hydatid cysts at age of 8 , treated with anthelmintic with good outcome. As far as her past medical history is concerned, there was a history of cervical plexus trauma at the age of 6 with monoparesis sequelae of the left arm.

She presented with progressive left hemiparesis 4 weeks earlier. On clinical exam, all deep tendon reflexes were normal. Proximal muscle strength of the left leg and the ipsilateral upper extremity was 3/5. Electromyography (EMG) showed abolition of motor and sensory responses of nerves SPE and SPI on the left upper limb.

MRI of the cervical spine showed intraspinal cystic lesion of extradural location lateralized to the left, extending from $\mathrm{C} 5$ to $\mathrm{T} 2$ causing a stenosis of the adjacent foramina, without contrast enhancement of the cyst wall (Figure 1).

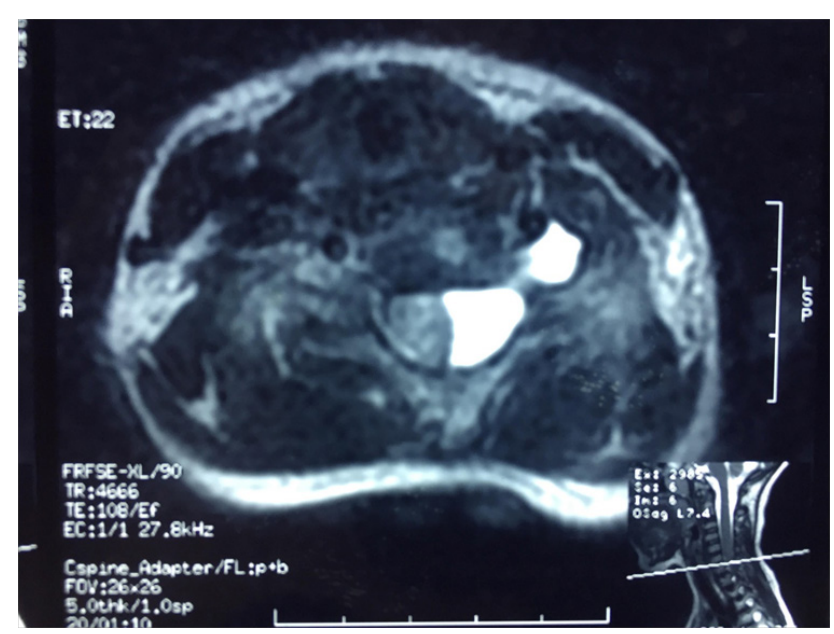

Figure I T2-weighted axial MRI showing an intraductal cystic lesion lateralized to the left and protruding in the adjacent neuro foramina. Squeezing the cervical spinal cord.

Based on the MRI finding and the history of patient, the diagnosis of spinal hydatid disease was suspected. The patient underwent a C4T2 laminotomy (Figure 2), intraoperatively we found cystic lesions strongly adhered to the dural mater with an appearance that was evoking congenital cysts. At this point, we opened the capsule and a clear CSF-like liquid came out from the cyst, we conducted a careful excision with dural plasty.

The histological examination showed fibrous tissue and the presence of neural elements, which is typical for perineural cysts. Postoperatively, the patient has improved significantly her left 
lower-limb strength. A postoperative MRI of the cervical spine was performed after 6 months showed no recurrence of the cyst (Figure 3).

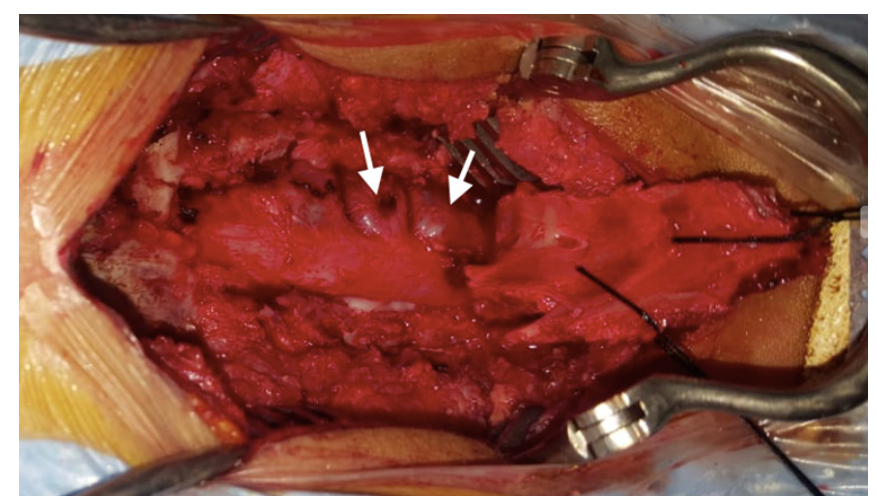

Figure 2 C4 to T2 laminotomy, and the cystic lesion that has a translucid wall (arrows).
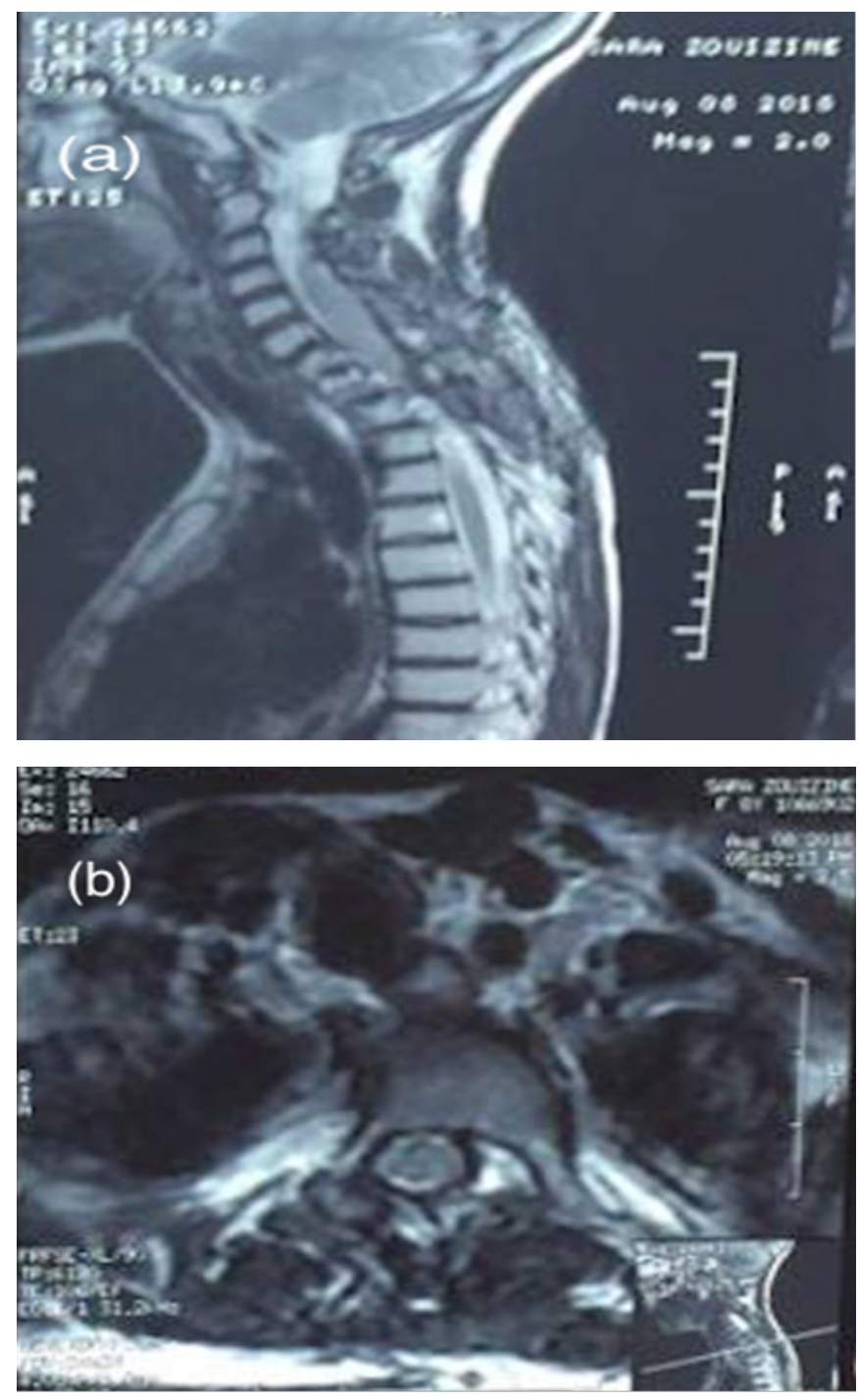

Figure 3 Sagittal (a) and axial (b) postoperative spinal MRI after 6 months showing the disappearance of the cyst and the pressure lifted on the cervical cord.

\section{Discussion}

Tarlov cysts, or perineural cysts, firstly described by I.M. Tarlov in 1938 as an incidental finding during his autopsy studies of the filum terminale. ${ }^{5}$ They are pathological fluid collections located between the peri and endoneurium, filled with CSF, therefore the signal is cerebrospinal fluid (CSF)-like signal on all MRI sequences. ${ }^{6}$

They are often multiple and are mainly located in the sacral region, cervical location is rare. In a systematic study Burdan et al. reported about a prevalence of $1.2 \%$ of cervical perineural cysts. ${ }^{7}$ They are symptomatic in $13 \%$ of cases according to Langdown et al. ${ }^{1}$

The exact physiopathology of perineural cyst remains unclear, and several hypotheses have been proposed. Tarlov suggested that hemosiderin deposition caused blockage of the venous drainage of the perineurium and epineurium after local trauma can lead to the development of these cysts. ${ }^{4}$ Others authors discuss a developmental or congenital origin. ${ }^{8}$

The onset of symptoms can be sudden or gradual, and are exacerbated by coughing, standing, and change of position, ${ }^{8}$ those symptoms depend on their location, and range from backache, perineal pain or sciatica to over cauda equina syndrome. ${ }^{5}$

$\mathrm{TC}$ is usually diagnosed using diagnostic imaging. X-ray can show bone erosion in the anterior or posterior part of the vertebral foramen. ${ }^{9}$ The CT scan may show CSF isodense cystic mass at the foramen. ${ }^{10}$ Myelography was used for the positive diagnosis of TC, it allowed the identification of the communication of the cyst with the subarachnoid space, and late filling phenomenon allowing the differential diagnosis with other cystic lesions of meningeal origin, which are not TC. ${ }^{11}$

Spinal MRI is currently the method of choice in diagnosis of perineural cysts, it shows a cystic lesion, located near the dorsal root ganglion with a hypointense signal through T1-weighted imaging, a hyperintense signal through-T2 weighted imaging, without godalinium enhancement.

The differential diagnosis is mainly with other spinal meningeal cysts. The classification of Nabor et al. ${ }^{12}$ differentiates three types; Type I: extradural cysts without nerve fiber, type Ia: arachnoid cyst extradural. Type Ib: meningocele sacred. Type II: extradural cysts containing nerve cells (TC). Type III: arachnoid cyst intradural. ${ }^{12}$

It is also important to distinguish with neurogenic tumors such as schwannoma, those solid tumors enhance after gadolinium injection, Joshi et al. reported about a central perineural cyst masquerading a tumor, the cyst was located intra spinally and caused compression of the cervical myelon. ${ }^{13}$

Till date, published treatment options for apparently symptomatic TC include medication, percutaneous procedures, and surgery. However, these methods are associated with various outcomes and complications. Mitra et al. ${ }^{14}$ described a conservative approach for a symptomatic cervical TC using oral steroids after initial ineffective course of NSAIDs. A six-day-course of oral steroids was given, leading to relief of symptoms, as far as, the upper extremity motor strength was concerned, but with a slight increase in the patient's sense of pain. ${ }^{14}$

Kim et al. ${ }^{15}$ performed a more invasive transforaminal epidural steroid injection for a case of symptomatic perineural cyst in the 
cervical spine. ${ }^{15}$ Epidural steroid injection was primarily employed to reduce neural inflammation causing radicular symptoms, but the follow-up MRI revealed a shrunken cyst in this case, which was an unexpected result of the intervention.

Jungwon Lee et al. ${ }^{16}$ Performed ultrasound-guided cervical elective nerve root block using local anesthetics and steroids without fenestration of the cyst in a case of symptomatic cervical TC which was resistant to medication. ${ }^{16}$ Therefore, ultrasound-guided cervical selective nerve root block is a safe and effective procedural option for the treatment of symptomatic cervical perineural cysts.

The microsurgical approach usually involves a small laminectomy with cyst fenestration, cyst imbrication, cyst neck ligation, cyst resection, and combinations of the above. ${ }^{8,17,18}$ Combining the evidence from 31 case series Laura E. Dowsett et al. ${ }^{19}$ found that after surgical treatment, the symptoms attributed to TC either completely or partially relieved in $83 \%$ of the cases. Complete resolution was experienced in $32 \%$ of cases, $50 \%$ had partial resolution, $16 \%$ had no improvement or worsening of symptoms and $0.4 \%$ had worsening of symptoms after surgery. ${ }^{19}$

However, the optimal management of symptomatic TC is still a matter of ongoing debate because of the variety of outcomes and complications for each method. Percutaneous aspiration of a perineural cyst can cause headaches owing to intracranial hypotension. ${ }^{2}$ Fibrin glue placement of perineural cysts is associated with several complications including aseptic meningitis and CSF leakage. ${ }^{20,21}$ Surgical excision of these cysts can also result in complications involving neural damage, pseudomeningocele, and intracranial hypotension. ${ }^{19}$

\section{Conclusion}

In conclusion, symptomatic cervical perineural cysts are extremely rare. In our patient's previous report, because of the rarity of the lesion, we did not suspect a TC at first, however, it should kept in mind in front of any intraspinal cystic lesion, and surgical excision may be an effective option for symptomatic cases.

\section{Competing interests}

The authors declare that they have no competing interests.

\section{Funding}

There was no funding applicable for this case report.

\section{Authors' contributions}

$\mathrm{MH}$ wrote the case report and provided data according to CARE guideline and provided the figures, $\mathrm{KC}$ collected the patient data and obtained the informed consent, FL co-wrote and reviewed this case report, $\mathrm{MH}$ and $\mathrm{KC}$ operated the patient, $\mathrm{MB}$ and $\mathrm{MFC}$ did the final revision of this case report. All authors reviewed the final manuscript. All authors read and approved the final manuscript.

\section{Acknowledgments}

None.

\section{References}

1. Langdown AJ, Grundy JR, Birch NC. The clinical relevance of Tarlov cysts. J Spinal Disord Tech. 2005;18(1):29-33.
2. Paulsen RD, Call GA, Murtagh FR. Prevalence and percutaneous drainage of cysts of the sacral nerve root sheath (Tarlov cysts). AJNR Am J Neuroradiol. 1994;15:293-297.

3. Gossner J. High prevalence of cervical perineural cysts on cervical spine MRI. Int J Anat Var. 2018;11(1):18-19.

4. Zibis A, Fyllos A, Arvanitis D. Symptomatic cervical perineural (Tarlov) cyst: a case report. Hippokratia. 2015;19:76-77.

5. Tarlov IM. Spinal perineurial and meningeal cysts. J Neurol Neurosurg Psychiatry. 1970;33(6):833-843.

6. Voyadzis JM, Bhargava P, Henderson FC. Tarlov cysts: a study of 10 cases with review of the literature. J Neurosurg. 2001;95(1 suppl):25-32.

7. Burdan F, Mocarska A, Janczarek M, et al. Incidence of spinal perineurial (Tarlov) cysts among East-European patients. PLOS ONE. 2013;8(8):e71514

8. Lucantoni C, Than KD, Wang AC, et al. Tarlov cysts: a controversial lesion of the sacral spine. Neurosurg Focus. 2011;31(6):E14.

9. Taveras JM, Wood EH. Diagnostic neuroradiology. 2nd ed. Vol 2. Williams and Wilkins: Baltimore; 1976. pp. 1139-45

10. Tabas JH, Deeb ZL. Diagnosis of sacral pe rineural cysts by computed tomography. J Comput Tomogr. 1986;10(3):255-259.

11. Landers J, Seex Br. Sacral perineural cysts: imaging and treatment options. J Neurosurg. 2002;16(2):182-185.

12. Nabors MW, Pait TG, Byrd EB, et al. Updated assessment and current classification of spinal meningeal cysts. J Neurosurg. 1988;68(3):366377 .

13. Poshi VP, Zanwar A, Karande A, et al. Cervical perineural cyst masquerading as a cervical spinal tumor. Asian Spine J. 2014;8(2):202205

14. Mitra R, Kirpalani D, Wedemeyer M. Conservative management of perineural cysts. Spine (Phila Pa 1976). 2008;33(16):E565-E568.

15. Kim K, Chun SW, Chung SG. A case of symptomatic cervical perineural (Tarlov) cyst: clinical manifestation and management. Skeletal Radiol. 2012;41(1):97-101.

16. Jungwon Lee, MD, Kilhyun Kim, MD, Saeyoung Kim, MD, Treatment of a symptomatic cervical perineural cyst with ultrasound-guided cervical selective nerve root block. Medicine. 2018;97(37):e12412.

17. Elsawaf A, Awad TE, Fesal SS. Surgical excision of symptomatic sacral perineurial Tarlov cyst: case series and review of the literature. Eur Spine J. 2016;25(11):1-8.

18. Seo DH, Yoon KW, Lee SK, et al. Microsurgical excision of symptomatic sacral perineurial cyst with sacral recapping laminec- tomy: a case report in technical aspects. J Korean Neurosurg Soc. 2014;55(2):110-113.

19. Laura E Dowsett, Fiona Clement, Stephanie Coward, et al. Effectiveness of Surgical Treatment for Tarlov Cysts : A Systematic Review of Published Literature. Clin Spine Surg. 2018;31(9):377-384.

20. Murphy K, Oaklander AL, Elias G, et al. Treatment of 213 patients with symptomatic Tarlov cysts by CT-guided percutaneous injection of fibrin sealant. Am J Neuroradiol. 2016;37(2):373-379.

21. PatelM, LouieW, RachlinJ. Percutaneous fibring luetherapy of meningeal cysts of the sacral spine. AJR Am J Roentgenol. 1997;168(2):367-370. 